\title{
Feeling Full or Empty Inside? Peran Perbedaan Individual dalam Struktur Pengalaman Afektif
}

\author{
Cleoputri Yusainy ${ }^{1}$ \\ Jurusan Psikologi Fakultas Ilmu Sosial dan Ilmu Politik \\ Universitas Brawijaya Malang
}

\begin{abstract}
Literatures on alexithymia and rumination are typically separated; however, the negative manifestations of both traits can potentially be attenuated by trait self-control. This experiment $(\mathrm{N}=85)$ aimed to explore the dynamics of self-reported alexythimia, rumination, and self-control toward an individual's structure of current affect. Participants were asked to rate affective valence and arousal of 60 stimuli from the International Affective Picture System (IAPS) using Self-Assessment Manikin (SAM). Results indicated that (1) trait alexythimia, rumination, and self-control were intercorrelated, (3) subtraits in alexythimia and rumination were associated with hypersensitivity towards affective stimuli, and (3) negative affect was prerequisite to the activation of self-control. This finding highlights that the roles of individual differences on affective experiences are context-dependent upon the combination of affective valence and arousal.
\end{abstract}

Keywords: arousal; trait alexithymia; trait rumination; trait self-control; valence

Abstrak. Trait alexithymia dan rumination umumnya diteliti secara terpisah, namun dampak buruknya terhadap pengalaman afektif secara potensial dapat dihambat oleh trait self-control. Penelitian ini bertujuan memetakan struktur pengalaman afektif berdasarkan perbedaan individual dalam trait alexithymia, rumination, dan self-control. Pengalaman afektif partisipan $(\mathrm{N}=85)$ dibangkitkan melalui teknik induksi visual International Affective Picture System (IAPS, 2008) yang mencakup 60 foto dari kombinasi dua dimensi afektif, yaitu valence (positif vs. netral vs. negatif) dan arousal (tinggi vs. rendah). Rating valence dan arousal diberikan dalam bentuk label non-verbal Self-Assessment Manikin. Hasil penelitian menunjukkan (1) terdapat interkorelasi antara trait alexithymia, rumination, dan self-control, (2) dimensi-dimensi pada trait alexythimia dan rumination memiliki asosiasi dengan hipersensitivitas terhadap stimulus afektif, dan (3) afek negatif dibutuhkan sebagai sinyal untuk mengaktivasi trait self-control. Temuan ini menggarisbawahi bahwa peran ketiga trait tersebut dalam struktur pengalaman afektif tidak muncul secara global namun bersifat kontekstual dari perspektif kombinasi valence dan arousal.

Kata kunci: arousal; trait alexithymia; trait rumination; trait self-control; valence

Unsur fundamental apa yang menyebabkan manusia cenderung menggenggam erat hal-hal yang ia sukai, dan sebaliknya, menendang dengan penuh kebencian hal-

\footnotetext{
${ }^{1}$ Korespondensi mengenai isi artikel ini dapat dilakukan melalui: cleo.yusainy@ub.ac.id
}

hal yang tidak ia sukai? Dalam perspektif Psikologi kontemporer, semua ide-ide kompleks, nilai, dan prinsip yang kita miliki, kenangan yang kita ingat, interaksi sosial yang kita bina, serta aspek-aspek lain dalam kehidupan tidak pernah bisa dilepaskan dari emosi-afek sebagai unsur 
yang paling fundamental. Survei terhadap 35 peneliti papan atas mendeskripsikan emosi sebagai, "jejaring saraf, sistem respons, dan perasaan/proses yang memotivasi dan mengorganisir kognisi dan perilaku" (Izard, 2010). Afek (dalam bahasa awam: perasaan) adalah pengalaman subjektif emosional yang intens.

Riset dengan data biologis terukur menyimpulkan bahwa proses primer emosi-afek bersumber dari jejaring saraf yang terkode secara genetik, sebagai antisipasi kebutuhan bertahan hidup (Damasio, 1999; Panksepp \& Biven, 2012). Emosi takut misalnya, memungkinkan nenek moyang kita bereaksi secara cepat saat dihadang binatang buas. Emosi seksual memicu kegiatan reproduksi untuk mewariskan genetik keluarga. Setelah melalui proses belajar (sekunder), pengalaman afektif yang mulanya bersifat independen dari pemaknaan kognitif kemudian berkembang. Emosi menjadi sinyal yang mempersiapkan subjek agar menampilkan respons sesuai tuntutan lingkungan sekaligus mengarahkan atensinya kepada cues lingkungan yang ia anggap penting (Bradley, 2009). Agar fungsi emosi menjadi efektif, kualitas yang harus dimiliki adalah (1) mengalami aktivasi ketika dibutuhkan, dan (2) mengalami deaktivasi saat situasi lingkungan berubah (Williams, 2010).

Literatur Psikologi mengenai emosiafek umumnya berfokus pada proses tersier, yaitu label yang secara sadar diberikan oleh subjek terhadap stimulus afektif berdasarkan model circumplex dari Feldman Barrett dan Russell (1999). Dalam model ini, afek digambarkan sebagai kombinasi antara dimensi valence yang bergerak dari perasaan menyenangkan (positif) sampai tidak menyenangkan (negatif) dan dimensi arousal yang merujuk pada perasaan energik. Sebagai contoh, perasaan gembira dan damai sama-sama dimunculkan oleh stimulus dengan valence positif, namun perasaan gembira beroperasi pada level arousal tinggi sedangkan perasaan damai beroperasi pada level arousal rendah. Di sisi lain, kombinasi perasaan negatif dan arousal tinggi memicu perasaan marah, kombinasi perasaan negatif dan arousal rendah memicu perasaan sedih. Stimulus afektif bisa berupa orang, kondisi, benda, atau peristiwa; nyata atau imajiner, di masa lalu, masa depan, atau saat ini (Russell, 2003).

Masalah terjadi ketika subjek memperlakukan rekonstruksi mental atas masa lalu dan masa depan sebagai ancaman nyata yang harus diatasi saat ini (Williams, 2010). Akibatnya, suatu emosi menjadi episode yang berkelanjutan tanpa kehadiran stimulus yang relevan, sementara cues lingkungan yang seharusnya diberi atensi malah menjadi terabaikan. Pada titik tertentu, ketidakmampuan mengelola pengalaman afektif dapat mengganggu fungsi normal kehidupan. Satu dari empat penduduk Inggris diprediksi pernah mengalami gangguan mental emosional mulai tingkat ringan sampai berat, dalam durasi singkat maupun lama (Department of Health, 2011). Di Indonesia, hasil Riset Kesehatan Dasar mengungkap bahwa prevalensi gangguan mental emosional adalah sebesar 6\% (Badan Penelitian \& Pengembangan Kesehatan, 2013). Gangguan mental emosional amat terkait dengan beragam kasus psikopatologi, maladaptasi sosial, dan bahkan penyakit fisik (Gross, 2007).

Fokus pertama penelitian ini adalah mengetahui peran trait alexithymia dan rumination dalam struktur pengalaman afektif. Kedua trait ini bukan merupakan diagnosis psikiatri dan dapat ditemukan 
pada populasi normal, namun baik alexithymia (lihat Freund, 2012) maupun rumination (Nolen-Hoeksema, Wisco, \& Lyubomirsky, 2008) diidentifikasi sebagai faktor risiko bagi banyak gangguan. Subjek dengan kecenderungan alexithymia mengalami kesulitan mengidentifikasi, mendeskripsikan, dan menginterpretasikan perasaannya sendiri (Bagby, Parker, \& Taylor, 1994), sehingga mendorong underengagement terhadap stimulus afektif. Sebaliknya, over-engagement terjadi pada subjek dengan level rumination yang tinggi, akibat adanya pemikiran repetitif mengenai sebab, akibat, dan simtom dari afek negatif yang ia alami (NolenHoeksema, 1991). Walaupun terkesan sebagai kecenderungan yang berlawanan (under-engagement vs. over-engagement), kedua trait ini berakar dari ketidakmampuan mengelola pengalaman afektif. Belum dihasilkan temuan konsisten mengenai apakah defisit terkait alexithymia dan rumination muncul pada pengalaman afektif secara global atau pada stimulus afektif dengan kombinasi valence dan arousal tertentu. Kontribusi kedua trait ini masih relatif jarang dibandingkan dalam satu studi.

Di sisi lain, literatur terkini mengkonseptualisasikan self-control sebagai salah satu trait adaptif utama yang tergantung kepada emosi-afek. Self-control merujuk pada kapasitas untuk mengendalikan proses mental dan perilaku diri sesuai dengan standar yang ditetapkan (Inzlicht \& Legault, 2014; Tangney, Baumeister, \& Boone, 2004). Individu dengan trait selfcontrol tinggi menampilkan sikap disiplin, dapat diandalkan, bekerja keras, dan sifatsifat lain yang dibutuhkan dalam berbagai domain kehidupan (De Ridder, LensveltMulders, Finkenauer, Stok, \& Baumeister, 2012; Moffitt et al., 2011). Aktivasi selfcontrol membutuhkan kemampuan moni- toring terhadap konflik atau kesenjangan antara diri dengan standar perilaku (Baumeister \& Alghamdi, 2015). Kegagalan melakukan monitoring konflik dapat menurunkan self-control, dan sebaliknya, partisipan yang mengikuti latihan peningkatan kemampuan monitoring pengalaman afektif lebih mampu mengontrol diri dari impuls agresif saat diprovokasi (Yusainy \& Lawrence, 2015). Kontribusi trait self-control dalam struktur pengalaman afektif adalah fokus kedua penelitian ini.

Kendala utama intervensi yang ditujukan secara langsung terhadap trait alexithymia (Swart, Kortekaas, \& Aleman, 2009) dan rumination (Nolen-Hoeksema et al., 2008) adalah sifat dari keduanya yang cenderung stabil. Sebaliknya, subjek dapat dilatih untuk meningkatkan trait selfcontrol melalui latihan sederhana yang dilakukan secara mandiri, seperti latihan memperbaiki postur tubuh, menggunakan tangan yang nondominan dalam tugas sehari-hari, dan menghindari kata makian (Baumeister, Gailliot, DeWall, \& Oaten, 2006). Dengan demikian, trait self-control memiliki potensi menghambat efek buruk dari trait alexythimia dan rumination sebelum berkembang menjadi episode gangguan mental emosional serius.

Secara spesifik, penelitian ini bertujuan untuk terlebih dahulu menguji pola korelasi antara trait alexithymia, rumination, dan self-control (Hipotesis 1), kemudian mengetahui sejauh mana peran trait alexithymia dan rumination dalam struktur pengalaman afektif (Hipotesis 2), serta memetakan kontribusi trait self-control dalam struktur pengalaman afektif setelah memperhitungkan peran trait alexithymia dan rumination (Hipotesis 3). Asosiasi trait alexithymia, rumination, dan self-control serta peran ketiga trait ini dalam struktur pengalaman afektif (dimensi valence dan 
arousal stimulus) diuji pada level trait global dan level dimensi dari masingmasing trait.

\section{Metode}

Penelitian ini menggunakan within-subjects experimental design dalam setting laboratorium. Partisipan penelitian adalah mahasiswa Universitas B yang direkrut melalui poster yang dipublikasikan di lingkungan kampus. Jumlah partisipan final adalah 85, terdiri atas 32 laki-laki $(37,647 \%)$ dan 53 perempuan $(62,353 \%)$, dengan usia rerata $M=20,670$ tahun $(S D=$ 1,229; rentang 18-23 tahun).

\section{Prosedur penelitian}

Partisipan hadir di laboratorium komputer secara berkelompok berdasarkan jadwal yang telah disepakati sebelumnya. Setelah membaca informasi mengenai eksperimen, partisipan diminta menandatangani formulir persetujuan, mengisi data demografis, serta melengkapi tiga kuesioner self-reported untuk mengukur trait dengan urutan penyajian (1) Brief SelfControl Scale (SCS: Tangney et al., 2004), (2) Toronto Alexithymia Scale (TAS-20: Taylor, et al., 2003), dan (3) Ruminative Response Scales (RRS: Treynor, Gonzalez, \& NolenHoeksema, 2003). Kuesioner yang bersifat lebih sensitif sengaja disajikan pada urutan akhir untuk mengurangi resistensi respons.

Partisipan kemudian menerima stimulus visual berupa 60 foto dari International Affective Picture System (IAPS: Lang, Bradley, \& Cuthbert, 2008) yang ditampilkan secara random. Setiap foto muncul selama 6 detik. Segera setelah foto menghilang dari layar monitor, partisipan diberi 10 detik untuk menilai rating SelfAssessment Manikin (SAM: Lang, 1980) dari dimensi valence dan arousal setiap foto.
Instrumen IAPS dan rating SAM dipresentasikan di layar komputer dengan menggunakan bahasa pemrograman dasar Phyton. Debrief mengenai hipotesis penelitian dilakukan bersamaan dengan pengumuman pemenang prize draw untuk tiga partisipan.

\section{Kuesioner trait}

Trait self-control, alexytimia, dan rumination diukur melalui adopsi ketiga kuesioner yang mencakup proses translate, back translate, dan uji keterbacaan. Blue-print kuesioner ditampilkan pada Tabel 1.

\section{Trait self-control}

Self-Control Scale versi Brief (Brief SCS) disusun oleh June P. Tangney, Roy F. Baumeister, dan Angie Luzio Boone tahun 2004. Rentang konten yang tercakup pada Brief SCS adalah kontrol pikiran, kontrol emosional, kontrol impuls, regulasi performa, dan mengubah kebiasaan. Partisipan memberikan respons terhadap 13 pernyataan yang merefleksikan kebiasaan sehari-hari (contoh, "Saya mampu bekerja secara efektif untuk mencapai sasaran jangka panjang") dalam skala Likert 5poin $(1=$ tidak sama sekali dan 5 = sangat $)$. Makin tinggi skor Brief SCS, makin tinggi trait self-control yang dilaporkan oleh partisipan. Dibandingkan kuesioner trait selfcontrol lain, SCS menunjukkan relasi yang stabil dengan beragam perilaku yang membutuhkan self-control (De Ridder et al., 2012). Skor reliabilitas Brief SCS dalam penelitian ini adalah 0,745 .

\section{Trait alexythimia}

Toronto Alexithymia Scale (TAS-20) disusun oleh R. Michael Bagby, James D. A. Parker, dan Graeme J. Taylor tahun 1994. Kuesioner ini terdiri dari tiga dimensi alexythimia yaitu Difficulty Identifying 
Tabel 1.

Blue-print kuesioner perbedaan individual

\begin{tabular}{|c|c|c|c|c|}
\hline \multirow{2}{*}{ Kuesioner } & \multirow{2}{*}{ Dimensi } & \multirow{2}{*}{ Definisi } & \multicolumn{2}{|c|}{ Nomer butir } \\
\hline & & & Favorable & Unfavorable \\
\hline $\begin{array}{l}\text { Brief Self- } \\
\text { Control Scale } \\
\text { (Brief SCS) }\end{array}$ & Unidimensi & $\begin{array}{l}\text { Kapasitas untuk } \\
\text { mengendalikan proses mental } \\
\text { dan perilaku diri sendiri. }\end{array}$ & $1,6,8,11$ & $\begin{array}{c}2,3,4,5,7,9 \\
10,12,13\end{array}$ \\
\hline \multirow[t]{3}{*}{$\begin{array}{l}\text { Toronto } \\
\text { Alexithymia } \\
\text { Scale (TAS-20) }\end{array}$} & $\begin{array}{l}\text { Dfficulty } \\
\text { identifying feelings } \\
\text { (DIF) }\end{array}$ & $\begin{array}{l}\text { Kesulitan mengidentifikasi } \\
\text { perasaan. }\end{array}$ & $\begin{array}{c}1,3,6,7,9 \\
13,14\end{array}$ & \\
\hline & $\begin{array}{l}\text { Difficulty } \\
\text { describing feelings } \\
\text { (DDF) }\end{array}$ & $\begin{array}{l}\text { Kesulitan mendeskripsikan } \\
\text { perasaan. }\end{array}$ & $2,11,12,17$ & 4 \\
\hline & $\begin{array}{l}\text { Externally oriented } \\
\text { cognitive style of } \\
\text { thinking }(\mathrm{EOT})^{*}\end{array}$ & $\begin{array}{l}\text { Kecenderungan merespon } \\
\text { stimulus dari luar saja dan } \\
\text { mengabaikan pengalaman } \\
\text { afektif. }\end{array}$ & $8,15,16,20$ & $5,10,18,19$ \\
\hline \multirow{2}{*}{$\begin{array}{l}\text { Ruminative } \\
\text { Response Scales } \\
\text { (RRS) }\end{array}$} & Brooding & $\begin{array}{l}\text { Terus-menerus mengkritik } \\
\text { mood diri sendiri. }\end{array}$ & $1,3,6,7,8$ & \\
\hline & Reflection & $\begin{array}{l}\text { Kontemplasi terhadap mood } \\
\text { diri sendiri dengan fokus pada } \\
\text { penyelesaian masalah. }\end{array}$ & $2,4,5,9,10$ & \\
\hline
\end{tabular}

Feelings (DIF; 7 butir, contoh "Saya bingung dengan emosi yang saya rasakan"); Difficulty Describing Feelings (DDF; 5 butir, contoh "Sulit bagi saya untuk mengekspresikan perasaan terdalam saya, bahkan kepada teman akrab"); dan Externally Oriented Cognitive Style Of Thinking (EOT; 8 butir, contoh "Saya lebih suka mendiskusikan tentang aktivitas harian orang lain daripada perasaan mereka"). Partisipan memberikan nilai pada skala Likert 5-poin dari rentang "sangat tidak setuju" sampai "sangat setuju". Skor TAS-20 yang makin tinggi mengindikasikan trait alexithymia yang makin tinggi. Kuesioner TAS-20 menunjukkan reliabilitas dan validitas faktorial lintas budaya dan bahasa (Taylor, Bagby, \& Parker, 2003), serta stabilitas pada sampel klinis dan non-klinis (Loas et al., 2001). Skor reliabilitas TAS-20 dalam penelitian ini adalah 0,807; sedangkan faktor DIF, DDF, dan EOT secara berturut- turut memiliki reliabiltas sebesar 0,835; 0,758; dan 0,167. Sebagaimana dalam penelitian TAS-20 versi non-Inggris lainnya, reliabilitas EOT penelitian ini tergolong rendah sehingga harus diinterpretasikan secara berhati-hati.

\section{Trait rumination}

Ruminative Response Scales (RRS) dikonstruksi oleh Wendy Treynor, Richard Gonzalez, dan Susan Nolen-Hoeksema tahun 2003 berdasarkan analisis sekunder data penelitian sebelumnya pada sampel komunitas (Nolen-Hoeksema, Larson, \& Grayson, 1999). Setelah konten yang mengandung tumpang tindih dengan konten depresi dihapus, dihasilkan dua faktor yaitu Brooding (5 butir, contoh "Saya berpikir 'Kenapa saya selalu bereaksi seperti ini?'"; konotasi negatif) dan Reflection (5 butir, contoh "Saya menganalisis peristiwa yang baru terjadi untuk memahami mengapa saya merasa 
tertekan"; konotasi netral). Setiap butir diberi nilai pada skala 4-poin ("hampir tidak pernah" sampai "hampir selalu") untuk menunjukkan sejauh mana butir tersebut merefleksikan pikiran dan perasaan partisipan saat sedih atau tertekan. Dimensi brooding umumnya dianalisis terpisah dengan reflection karena dinamika relasi yang berbeda antara kedua dimensi ini dengan gejala depresi (Whitmer \& Gotlib, 2011). Dalam penelitian ini diperoleh skor reliabiltas sebesar 0,745 (untuk RRS); 0,620 (Brooding); dan 0,614 (Reflection).

\section{Struktur pengalaman afektif}

Struktur pengalaman afektif dalam model circumplex adalah label yang secara sadar diberikan oleh subjek terhadap dimensi valence dan arousal suatu stimulus afektif (Feldman Barrett \& Russell, 1999). Valence adalah dimensi hedonis yang bergerak dari perasaan menyenangkan (positif) sampai tidak menyenangkan (negatif), sedangkan arousal (dikenal pula dengan istilah activation, aktivitas, atau energi) merujuk pada dimensi perasaan energik. Model circumplex mengasumsikan bahwa dimensi valence dan arousal bersifat orthogonal (independen secara statistik).

Pengalaman afektif partisipan dalam penelitian ini dibangkitkan melalui paparan terhadap stimulus International Affective Picture System (IAPS) versi terbaru (tahun 2008) yang dikembangkan oleh Peter J. Lang, Margaret M. Bradley, dan Bruce N. Cuthbert dari NIMH Center for Emotion and Attention di University of Florida. Instrumen IAPS terdiri dari total 1196 foto, dan telah menghasilkan konsistensi respons lintas budaya pada level label subjektif, psikofisiologis, perilaku, maupun neurofisiologis (Bradley \& Lang, 2007). Berbagai kombinasi foto IAPS dalam studi terpisah pada subjek dengan kecenderungan alexythimia (Heinzel et al., 2010) dan rumination (Ray et al., 2005) menemukan keterkaitan antara kemampuan pengelolaan emosi-afek dengan aktivasi area otak tertentu seperti dorsal anterior cingulate (kontrol kognitif dari pemrosesan emosional), insula (monitoring internal terhadap respons ketubuhan dan evaluasi internal terhadap afek), dan Brodmann area 47 . Riset trait self-control terdahulu (Friese \& Hofmann, 2009) juga telah menggunakan IAPS walaupun tidak spesifik untuk mengukur kontribusi trait ini dalam struktur pengalaman afektif.

Dimensi valence dan arousal dari setiap foto IAPS dapat dinilai menggunakan paradigma label nonverbal Self-Assessment Manikin (SAM; Gambar 1) dari Peter J. Lang (1980) pada label 9-poin (valence: skor 9 = ekspresi senyum dan 1 = ekspresi cemberut; arousal: skor $9=$ ekspresi antusias, mata terbuka lebar dan $1=$ ekspresi santai, mata mengantuk). Mean rating normatif yang tersedia pada manual IAPS kemudian diklasifikasikan dalam tiga kelompok, yaitu skor $<4$ digolongkan sebagai valence negatif/arousal rendah, skor 4-6 tergolong valence/arousal netral, skor> 6 tergolong valence positif/arousal tinggi. Untuk mengantisipasi ketidaksetaraan skor rerata antar kategori kombinasi akibat tidak berimbangnya proporsi foto dalam setiap kategori, peneliti membuat kategorisasi strata baru yaitu: pertama, Foto valence positif memiliki level arousal tinggi (PT) dan arousal rendah yang merupakan gabungan dari arousal rendah dan netral (PR). Pertama, foto valence netral memiliki level arousal tinggi yang merupakan gabungan dari arousal netral dan tinggi (UT) dan arousal rendah (UR). Kedua, foto valence negatif memiliki level foto arousal tinggi (NT) dan arousal rendah yang merupakan gabungan dari arousal rendah dan netral (NR). Ketiga, foto-foto kategori 
PT memicu perasaan gembira, aktif, dan antusias; PR memicu perasaan kalem, relaks, dan damai; NT memicu perasaan marah, takut, jijik, dan grief (meratap); NR memicu perasaan bosan, lelah, dan sedih.

Afek dengan valence netral berada pada titik sentral dari struktur pengalaman afektif (Panayiotou, 2008). Seluruh foto dalam manual IAPS yang berasal dari keenam kategori tersebut kemudian diseleksi dengan stratified random sampling sehingga menghasilkan 10 foto untuk setiap kategori pada sesi testing (total $=60$ foto; Tabel 2). Sebelum mengikuti sesi testing, partisipan terlebih dahulu mengikuti sesi practice. Dalam penelitian ini diperoleh skor reliabilitas rating valence sebesar 0,681 (PT); 0,695 (PR); 0,441 (UT); 0,529 (UR); 0,759 (NT); dan 0,539 (NR), serta reliabilitas rating arousal sebesar 0,820 (PT); 0,895 (PR); 0,727 (UT); 0,776 (UR); 0,888 (NT); dan 0,686 (NR).

Tabel 2.

Struktur International Affective Picture System (IAPS; Lang, Bradley, \& Cuthbert, 2008).

\begin{tabular}{|c|c|c|c|c|c|}
\hline \multirow[t]{3}{*}{ Sesi } & \multirow[t]{3}{*}{ Valence } & \multicolumn{4}{|c|}{ Arousal } \\
\hline & & \multicolumn{2}{|l|}{ Tinggi } & \multicolumn{2}{|l|}{ Rendah } \\
\hline & & Nomor foto & $\begin{array}{c}\text { Valence } M \\
(S D) ; \text { Arousal } \\
M(S D)\end{array}$ & Nomor foto & $\begin{array}{c}\text { Valence } M \\
(S D) ; \text { Arousal } \\
M(S D)\end{array}$ \\
\hline \multirow[t]{3}{*}{ Practice } & Positif & 1710 & & 1460 & \\
\hline & Netral & 7497 & & 2635 & \\
\hline & Negatif & 3400 & & 9001 & \\
\hline \multirow[t]{3}{*}{ Testing* } & Positif & $\begin{array}{l}\text { PT: 5621, 7405, 8030, } \\
8080,8186,8200,8370, \\
8470,8490,8501\end{array}$ & $\begin{array}{l}7,518(0,284) \\
6,645(0,362)\end{array}$ & $\begin{array}{l}\text { PR: 1441, 1600, 1750, } \\
2222,2299,2360,2388, \\
2530,5001,5760\end{array}$ & $\begin{array}{l}7,615(0,404) ; \\
3,855(0,266)\end{array}$ \\
\hline & Netral & $\begin{array}{l}\text { UT: } 1122,1645,2122, \\
2309,2616,5455,7077, \\
7211,8466,9468\end{array}$ & $\begin{array}{l}5,140(0,422) \\
4,631(0,304)\end{array}$ & $\begin{array}{l}\text { UR: } 1616,1675,2308, \\
2575,4325,5535,5661, \\
7081,7365,7506\end{array}$ & $\begin{array}{l}5,376(0,351) ; \\
4,208(0,376)\end{array}$ \\
\hline & Negatif & $\begin{array}{l}\text { NT: } 1300,3019,5971, \\
6230,6550,6570.1,6821, \\
9300,9622,9810\end{array}$ & $\begin{array}{l}2,750(0,513) \\
6,547(0,435)\end{array}$ & $\begin{array}{l}\text { NR: } 2205,2399,2490, \\
2722,2750,2900.1, \\
9000,9101,9220,9280\end{array}$ & $\begin{array}{l}2,858(0,632) \\
4,119(0,319)\end{array}$ \\
\hline
\end{tabular}

Ket.: Angka empat digit menunjukkan nomor foto IAPS yang telah dilengkapidengan Mdan $S D$ untuk dimensi valence dan arousal dari studinormatif IAPS.

$\mathrm{PT}=$ kombinasi valence positif-arousal tinggi; $\mathrm{PR}=$ kombinasi valence positif-arousal rendah; $\mathrm{UT}$ $=$ kombinasi valence netral-arousal tinggi; $\mathrm{UR}=$ kombinasi valence positif-arousal rendah; $\mathrm{NT}=$ kombinasi valence negatif-arousal tinggi; $\mathrm{NR}=$ kombinasi valence negatif-arousal rendah.

Paired sample t-test menunjukkan kesetaraan level valence antar kategori foto positif $(t=$ $0,732 ; p=0,483)$ setara dengan negatif $(t=0,370 ; p=0,720)$. Terdapat perbedaan signifikan level arousal antar kategori foto positif $(t=23,263 ; p<0,001)$ dan negatif $(t=12,660 ; p<0,001)$. Kategori PT dan NT berbeda dalam hal valence $(t=20,970 ; p<0,001)$ namun setara dalam arousal $(t=0,769 ; p=0,462)$. Kategori PR dan NR juga berbeda dalam hal valence $(t=20,378 ; p<$ $0,001)$ namun setara dalam arousal $(t=1,672 ; p=0,129)$.

*Urutan trial disajikan secara random kepada partisipan. 


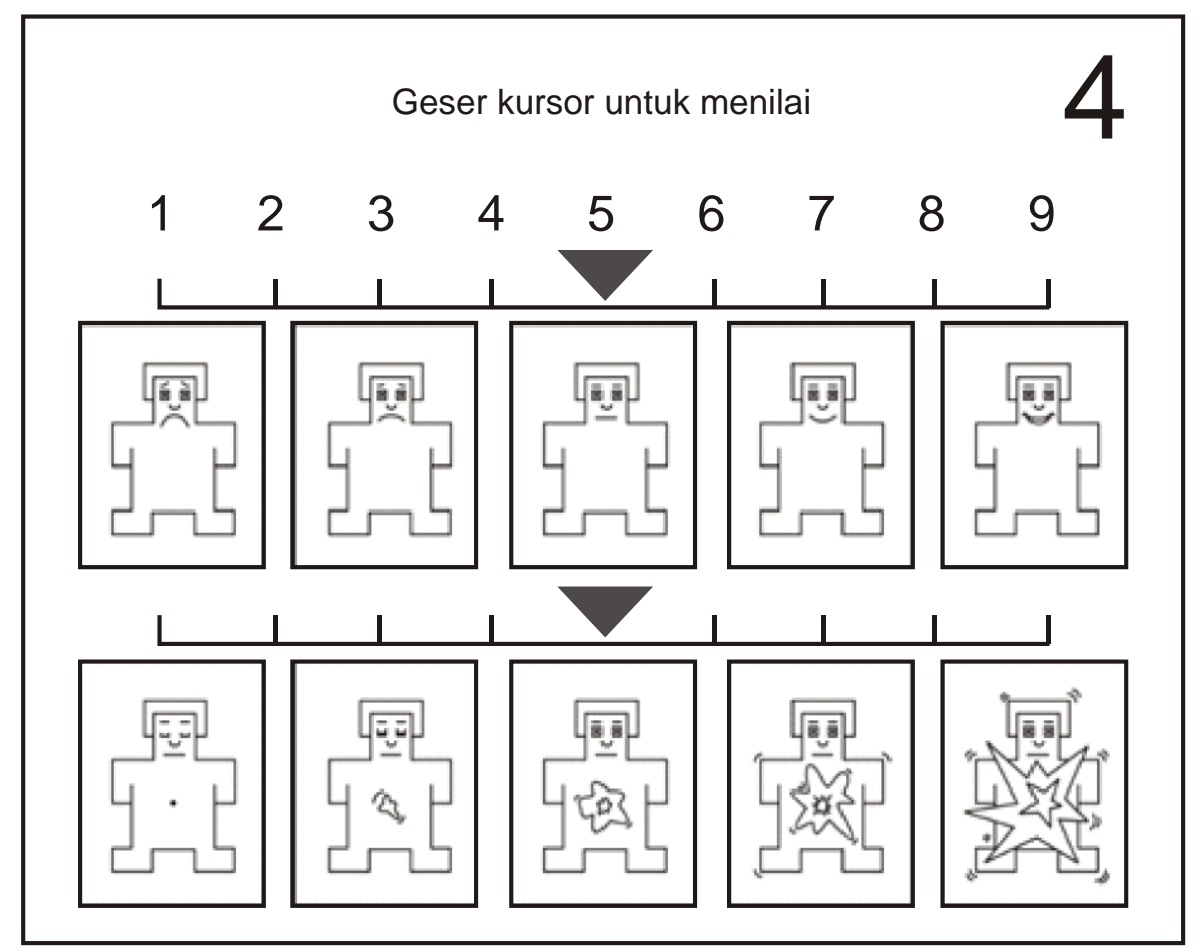

Gambar 1. Self-Assessment Manikin (SAM) untuk Menilai Dimensi Valence (Panel Atas) dan Arousal (Panel Bawah) Struktur Pengalaman Afektif (dikutip dari Lang, 1980).

\section{Hasil}

Korelasi antar trait. Zero order correlation ketiga trait (Hipotesis 1) disajikan pada Tabel 3. Trait alexythimia (TAS-20) berasosiasi positif dengan trait rumination (RRS), artinya makin sulit subjek melakukan identifikasi, memberikan deskripsi, dan menginterpretasikan pengalaman afektifnya, makin tinggi keterpakuan terhadap perasaan diri sendiri. Trait alexythimia berasosiasi negatif dengan trait self-control (Brief SCS), sehingga kesulitan memahami pengalaman afektif meningkat seiring penurunan kapasitas kontrol diri. Trait self-control tidak berasosiasi signifikan dengan trait rumination.

Asosiasi trait alexithymia dan rumination memunculkan pola yang unik pada level dimensi trait. Kesulitan mengidentifikasi perasaan (DIF) meningkat seiring kecenderungan melakukan kontemplasi (Reflection), sedangkan kesulitan mendeskripsikan perasaan (DDF) mening- kat seiring kritik terhadap mood diri sendiri (Brooding). Namun kontemplasi maupun kritik diri menurun ketika subjek sekadar merespons stimulus eksternal dan mengabaikan pengalaman afektifnya (EOT). Korelasi negatif antara traitalexythimia dan self-control muncul secara konsisten pada dimensi DIF dan DDF, namun tidak pada dimensi EOT. Tidak ditemukan asosiasi antara trait self-control dengan dimensi-dimensi rumination.

Asosiasi trait dan rating pengalaman afektif. Zero-order correlation trait alexithymia, rumination, dan self-control dengan rating partisipan terhadap stimulus IAPS ditampilkan pada Tabel 4 . Secara umum sangat sedikit korelasi yang signifikan antara ketiga trait dengan rating valence dan arousal IAPS. Trait alexythimia (TAS-20), khususnya dimensi DIF, berkorelasi negatif dengan level valence foto kategori PR, menandakan bahwa makin sulit subjek mengidentifikasi perasaannya, makin negatif respons yang 
Tabel 3.

Asosiasi trait alexithymia, rumination,dan self-control $(N=85)$

\begin{tabular}{lllllllll}
\hline \multicolumn{1}{c}{ Kuesioner } & \multicolumn{1}{c}{$(1)$} & \multicolumn{1}{c}{$(2)$} & \multicolumn{1}{c}{$(2 \mathrm{a})$} & \multicolumn{1}{c}{$(2 \mathrm{~b})$} & \multicolumn{1}{c}{$(2 \mathrm{c})$} & $(3)$ & \multicolumn{1}{c}{$(3 \mathrm{a})$} & $(3 \mathrm{~b})$ \\
\hline Brief SCS (1) & 1 & $-0,416^{* *}$ & $-0,466^{* * *}$ & $-0,326^{* *}$ & $-0,097$ & $-0,082$ & $-0,034$ & 0,061 \\
TAS-20 (2) & $-0,416^{* * *}$ & 1 & $0,908^{* * *}$ & $0,844^{* * *}$ & $0,523^{* * *}$ & $0,243^{*}$ & 0,122 & 0,151 \\
DIF (2a) & $-0,466^{* * *}$ & $0,908^{* * *}$ & 1 & $0,702^{* * *}$ & $0,252^{*}$ & $0,367^{* *}$ & 0,212 & $0,306^{* *}$ \\
DDF (2b) & $-0,326^{* *}$ & $0,844^{* * *}$ & $0,702^{* * *}$ & 1 & 0,182 & $0,285^{* *}$ & $0,243^{*}$ & 0,164 \\
EOT (2c) & $-0,097$ & $0,523^{* *}$ & $0,252^{*}$ & 0,182 & 1 & $-0,232^{*}$ & $-0,296^{* *}$ & $-0,262^{*}$ \\
RRS (3) & $-0,082$ & $0,243^{*}$ & $0,367^{* *}$ & $0,285^{* *}$ & $-0,232^{*}$ & 1 & $0,884^{* * *}$ & $0,879^{* * *}$ \\
Brooding (3a) & $-0,034$ & 0,122 & 0,212 & $0,243^{*}$ & $-0,296^{* *}$ & $0,884^{* * *}$ & 1 & $0,641^{* * *}$ \\
Reflection (3b) & 0,061 & 0,151 & $0,306^{* *}$ & 0,164 & $-0,262^{*}$ & $0,879^{* * *}$ & $0,641^{* * *}$ & 1 \\
$M(S D)$ & 3,057 & 2,747 & 2,684 & 2,993 & 2,648 & 2,512 & 2,548 & 2,468 \\
& $(0,475)$ & $(0,467)$ & $(0,726)$ & $(0,755)$ & $(0,364)$ & $(0,441)$ & $(0,481)$ & $(0,509)$ \\
\hline
\end{tabular}

Ket. Brief SCS = Brief Self-Control Scale; TAS-20 = Toronto Alexithymia Scale: DIF = Difficulty Identifying Feelings, DDF = Difficulty Describing Feelings, EOT = Externally oriented cognitive style of thinking; RRS = Ruminative Response Scale.

Partisipan perempuan dan laki-laki melaporkanpola asosiasi antar trait yang serupa, sertalevel trait self-control, alexythimia, dan rumination yang setara $(p s>0,272)$.

${ }^{*} p<0,05,{ }^{* *} p<0,01,{ }^{* * *} p<0,001$

Tabel 4.

Asosiasi trait alexithymia, rumination, dan self-control dengan rating afektif $(N=85)$

\begin{tabular}{lllllll}
\hline \multirow{2}{*}{ Kuesioner } & \multicolumn{7}{c}{ Rating valence; arousal } \\
\cline { 2 - 7 } & \multicolumn{1}{c}{ PT } & \multicolumn{1}{c}{ PR } & UT & UR & NT & NR \\
\hline Brief SCS & $-0,038 ;-0,058$ & 0,$096 ;-0,051$ & $-0,158 ; 0,057$ & $-0,176 ; 0,055$ & 0,$009 ;-0,100$ & 0,$048 ;-0,069$ \\
TAS-20 & $-0,004 ; 0,116$ & $-0,241^{*} ; 0,090$ & 0,$082 ; 0,048$ & 0,$004 ;-0,001$ & 0,$126 ; 0,141$ & $-0,052 ; 0,025$ \\
DIF & $-0,004 ; 0,137$ & $-0,224^{*} ; 0,093$ & 0,$089 ; 0,068$ & $-0,015 ; 0,046$ & 0,$130 ; 0,212$ & $-0,081 ; 0,105$ \\
DDF & $-0,115 ; 0,092$ & $-0,146 ; 0,062$ & 0,$012 ; 0,091$ & $-0,072 ; 0,086$ & 0,$120 ; 0,141$ & $-0,006 ; 0,078$ \\
EOT & 0,$145 ; 0,015$ & $-0,192 ; 0,043$ & 0,$090 ;-0,080$ & 0,$134 ;-0,193$ & 0,$021 ;-0,100$ & $-0,020 ;-0,203$ \\
RRS & 0,$129 ; 0,106$ & 0,$027 ; 0,072$ & $-0,149 ; 0,143$ & $-0,086 ; 0,187$ & $-0,025 ; 0,126$ & $-0,083 ; 0,151$ \\
Brooding & 0,$127 ; 0,041$ & 0,$072 ;-0,005$ & $-0,193 ; 0,116$ & $-0,112 ; 0,114$ & $-0,073 ; 0,163$ & $-0,089 ; 0,163$ \\
Reflection & 0,$030 ; 0,101$ & 0,$002 ; 0,073$ & $-0,082 ; 0,184$ & $-0,047 ; 0,226 *$ & 0,$023 ; 0,040$ & $-0,005 ; 0,094$ \\
M (SD) & $7,344(0,796) ;$ & $7,385(0,654) ;$ & $4,880(0,825) ;$ & $5,551(0,652) ;$ & $2,624(0,854) ;$ & $3,060(0,680) ;$ \\
& $6,442(1,204)$ & $4,201(1,709)$ & $5,151(1,130)$ & $4,569(1,049)$ & $6,561(1,364)$ & $4,197(1,004)$ \\
\hline
\end{tabular}

Ket.: Brief SCS = Brief Self-Control Scale; TAS-20 = Toronto Alexithymia Scale: DIF = Difficulty identifying feelings, $\mathrm{DDF}=$ Difficulty describing feelings, $\mathrm{EOT}=$ Externally oriented cognitive style of thinking; RRS = Ruminative Response Scale.

$\mathrm{PT}=$ kombinasi valence positif-arousal tinggi $; \mathrm{PR}=$ kombinasi valence positif-arousal rendah; $\mathrm{UT}$ = kombinasi valence netral-arousal tinggi; $\mathrm{UR}=$ kombinasi valence positif-arousal rendah; $\mathrm{NT}=$ kombinasi valence negatif-arousal tinggi; $\mathrm{NR}=$ kombinasi valence negatif-arousal rendah.

Partisipan perempuan cenderung memberikan rating valence lebih rendah $(p s<0,016)$, kecuali untuk kategori PT. Tidak ada perbedaan rating arousal $(p>0,325)$ antar jenis kelamin.

${ }^{*} p<0,05,{ }^{* *} p<0,01,{ }^{* * *} p<0,001$

ia tampilkan terhadap stimulus yang memicu perasaan kalem, relaks, dan damai. Sebaliknya, dimensi Reflection pada trait rumination berkorelasi positif dengan level arousal foto kategori UR, artinya subjek yang sering berkontemplasi cenderung menilai stimulus netral sebagai hal yang lebih membangkitkan energi. Trait rumination tidak berkorelasi dengan rating afektif, namun dimensi Reflection pada trait ini berkorelasi positif dengan level arousal foto kategori UR, artinya subjek yang sering berkontemplasi cenderung menilai stimulus netral sebagai 
hal yang lebih membangkitkan energi. Tidak ada korelasi trait self-control dan rating valence maupun arousal.

Peran trait dalam struktur pengalaman afektif. Hierarchical regression analysis dilakukan untuk menguji peran trait alexithymia dan rumination terhadap struktur pengalaman afektif (Hipotesis 2), dan kontribusi trait self-control terhadap struktur pengalaman afektif setelah memperhitungkan peran trait alexithymia dan rumination (Hipotesis 3). Untuk mengendalikan peran potensial jenis kelamin partisipan terhadap kategori stimulus tertentu (lihat kembali Tabel 4), variabel ini dimasukkan sebagai prediktor Step 1 dalam analisis yang relevan. Untuk kategori stimulus yang tidak berasosiasi dengan jenis kelamin, trait alexythimia dan rumination dimasukkan pada Step 1, Step 2 berisi trait self-control.

Hasil analisis pada level trait global ditunjukkan pada Tabel 5. Trait alexythimia (TAS-20) dan rumination (RRS) tidak memiliki peran memprediksi rating valence maupun rating arousal. Kontribusi trait selfcontrol muncul pada rating valence kategori UR, yaitu makin tinggi kapasitas kontrol diri, makin negatif penilaian terhadap stimulus netral dengan arousal rendah. Trait self-control tidak berkontribusi memprediksi rating arousal. Sebagai tambahan, dibandingkan partisipan laki-laki, perempuan cenderung menilai kategori PR secara lebih positif, namun menilai stimulus dengan valence netral dan negatif secara lebih negatif.

Pada level dimensi trait, rating valence kategori PT berasosiasi positif dengan dimensi EOT pada trait alexythimia $(B=$ 0,570; $p<0,05)$ dan dimensi Brooding pada trait rumination $(B=0,635 ; p<0,001)$. Artinya subjek yang sekedar merespon stimulus dari luar sekaligus sering mengkritik mood diri sendiri cenderung memberikan penilaian lebih positif terhadap stimulus yang membangkitkan perasaan gembira, aktif, antusias. Trait selfcontrol kembali menunjukkan asosiasi negatif dengan rating valence kategori UR $(B=-0,362 ; p<0,05)$, dan partisipan perempuan kembali memberikan rentang rating valence yang lebih luas. Rating arousal kategori NT berasosiasi positif dengan dimensi DIF dari trait alexythimia $(B=0,678 ; p<0,05)$. Artinya kesulitan mengidentifikasi perasaan meningkat sering dengan arousal akibat paparan stimulus yang membangkitkan perasaan marah, takut, jijik, dan meratap.

\section{Diskusi}

Penelitian ini bertujuan memetakan dinamika peran trait alexithymia, rumination, dan self-control dalam struktur pengalaman afektif ditinjau dari perspektif valence dan arousal stimulus afektif. Analisis korelasi antar trait menghasilkan asosiasi positif dua trait yang sama-sama merupakan faktor risiko dari banyak gangguan mental-emosional yaitu alexythimia dan rumination. Kesulitan subjek dengan kecenderungan alexythimia melakukan identifikasi, memberikan deskripsi, dan membuat interpretasi mengenai perasaan diri sendiri (Bagby et al., 1994) mengakibatkan jumlah informasi yang dimiliki cenderung terbatas. Padahal informasi dari stimulus afektif diperlukan agar perilaku yang ditampilkan sesuai tuntutan lingkungan (Bradley, 2009). Dalam konteks alexythimia, rumination yang melibatkan pemikiran repetitif tentang diri sendiri (Nolen-Hoeksema, 1991) dapat dimaksudkan sebagai strategi untuk memeroleh lebih banyak informasi yang dibutuhkan. Sebagai catatan, intervensi trait aleythimia perlu memperhatikan asosiasi negatif salah satu dimensi trait ini, yaitu Externally oriented cognitive 
Tabel 5.

Hierachical regression analysis rating afektif dengan prediktor trait

\begin{tabular}{|c|c|c|c|c|c|c|}
\hline Kategori stimulus & $D V$ & Step & Prediktor & $\Delta R^{2}$ & Total $R^{2}$ & Final beta \\
\hline \multirow[t]{2}{*}{$\mathrm{PT}$} & Rating valence & 1 & TAS-20 dan RRS & 0,018 & 0,018 & $-0,100,0,251$ \\
\hline & & 2 & Brief SCS & 0,002 & 0,020 & $-0,085$ \\
\hline \multirow[t]{3}{*}{ PR } & & 1 & Jenis kelamin & $0,067^{*}$ & 0,067 & 0,301 \\
\hline & & 2 & TAS-20 dan RRS & 0,048 & 0,114 & $0,-315,0,082$ \\
\hline & & 3 & Brief SCS & 0,001 & 0,114 & 0,009 \\
\hline \multirow[t]{3}{*}{ UT } & & 1 & Jenis kelamin & $0,279^{* * *}$ & 0,279 & $-0,881$ \\
\hline & & 2 & TAS-20 dan RRS & 0,009 & 0,288 & $-0,058,-0,174$ \\
\hline & & 3 & Brief SCS & 0,026 & 0,314 & $-0,308$ \\
\hline \multirow[t]{3}{*}{ UR } & & 1 & Jenis kelamin & $0,169^{* * *}$ & 0,169 & $-0,569$ \\
\hline & & 2 & TAS-20 dan RRS & 0,003 & 0,172 & $-0,195,-0,030$ \\
\hline & & 3 & Brief SCS & $0,045^{*}$ & 0,217 & $-0,332$ \\
\hline \multirow[t]{3}{*}{ NT } & & 1 & Jenis kelamin & $0,113^{* *}$ & 0,113 & $-0,563$ \\
\hline & & 2 & TAS-20 dan RRS & 0,008 & 0,120 & $0,208,-0,019$ \\
\hline & & 3 & Brief SCS & 0,003 & 0,123 & 0,101 \\
\hline \multirow[t]{3}{*}{ NR } & & 1 & Jenis kelamin & $0,065^{*}$ & 0,065 & $-0,360$ \\
\hline & & 2 & TAS-20 dan RRS & 0,008 & 0,073 & $-0,098,-0,053$ \\
\hline & & 3 & Brief SCS & 0,001 & 0,073 & 0,026 \\
\hline \multirow[t]{2}{*}{$\mathrm{PT}$} & Rating arousal & 1 & TAS-20 dan RRS & 0,020 & 0,020 & $0,235,0,225$ \\
\hline & & 2 & Brief SCS & 0,001 & 0,020 & $-0,034$ \\
\hline \multirow[t]{2}{*}{ PR } & & 1 & TAS-20 dan RRS & 0,011 & 0,011 & $0,254,0,206$ \\
\hline & & 2 & Brief SCS & 0,001 & 0,011 & $-0,064$ \\
\hline \multirow[t]{2}{*}{ UT } & & 1 & TAS-20 dan RRS & 0,037 & 0,037 & $-0,053,0,469$ \\
\hline & & 2 & Brief SCS & 0,003 & 0,040 & 0,134 \\
\hline \multirow[t]{2}{*}{ UR } & & 1 & TAS-20 dan RRS & 0,021 & 0,021 & $0,128,0,352$ \\
\hline & & 2 & Brief SCS & 0,007 & 0,027 & 0,215 \\
\hline \multirow[t]{2}{*}{$\mathrm{NT}$} & & 1 & TAS-20 dan RRS & 0,029 & 0,029 & $0,279,0,304$ \\
\hline & & 2 & Brief SCS & 0,002 & 0,031 & $-0,148$ \\
\hline \multirow[t]{2}{*}{ NR } & & 1 & TAS-20 dan RRS & 0,023 & 0,023 & $-0,093,0,354$ \\
\hline & & 2 & Brief SCS & 0,005 & 0,028 & $-0,157$ \\
\hline
\end{tabular}

Ket.: Brief SCS $=$ Brief Self-Control Scale; TAS-20 $=$ Toronto Alexithymia Scale; RRS $=$ Ruminative Response Scale.

$\mathrm{PT}=$ kombinasi valence positif-arousal tinggi; $\mathrm{PR}=$ kombinasi valence positif-arousal rendah; UT = kombinasi valence netral-arousal tinggi; $\mathrm{UR}=$ kombinasi valence positif-arousal netral; $\mathrm{NT}=$ kombinasi valence negatif-arousal tinggi; $\mathrm{NR}=$ kombinasi valence negatif-arousal rendah.

${ }^{*} p<0,05,{ }^{* *} p<0,01$.

style of thinking (EOT) dengan dimensidimensi trait rumination. Penurunan kebiasaan subjek untuk sekadar merespon stimulus dari luar dan mengabaikan pengalaman afektifnya (EOT) cenderung sejalan dengan peningkatan kritik terhadap mood diri sendiri (Brooding) dan kontemplasi diri (Reflection).

Trait alexythimia menunjukkan asosiasi negatif dengan self-control, salah satu trait adaptif utama individu. Defisit dalam tugas-tugas yang membutuhkan selfcontrol ditunjukkan subjek alexythimia akibat kesulitannya mengenali dan membedakan perasaan diri sendiri (Henry, Phillips, Crawford, Theodorou, \& Summers, 2006). Hal ini sejalan dengan asosiasi negatif yang konsisten muncul antara trait self-control dengan dimensi Difficulty Identifying Feelings (DIF) dan 
Difficulty Describing Feelings (DDF) pada trait alexythimia. Keterampilan melakukan identifikasi dan memberikan deskripsi atas perasaan dapat terasah secara simultan karena monitoring konflik yang harus terus-menerus dijalankan dalam proses self-control. Di sisi lain, tidak signifikannya asosiasi trait self-control dengan rumination, maupun dengan dimensi Brooding dan Reflection, mengindikasikan bahwa relasi kedua trait tersebut mungkin membutuhkan konteks tema yang tidak terukur melalui penelitian ini. Dalam the multiple systems model of angry rumination (Denson, 2013) misalnya, individu dengan trait self-control rendah cenderung sulit mengendalikan pemikiran repetitif yang terkait dengan tema yang membangkitkan perasaan marah atau pemikiran untuk membalas dendam.

Analisis selanjutnya menemukan bahwa peran trait alexithymia dan rumination terjadi pada level dimensi trait, terhadap kombinasi valence dan arousal stimulus afektif tertentu. Rating valence yang lebih positif dilaporkan pada kategori stimulus positif-arousal tinggi seiring peningkatan kecenderungan berfokus pada dunia luar (dimensi EOT pada trait alexythimia) dan banyaknya kritik terhadap diri (dimensi Brooding pada trait rumination). Temuan ini berbeda dengan prediksi Peneliti bahwa trait alexythimia dan rumination seharusnya menurunkan rating valence stimulus afektif. Walaupun riset tentang keterkaitan kedua trait ini dengan afek positif masih jarang dilakukan, mekanisme peningkatan afek positif dapat ditampilkan sebagai kompensasi atas kesulitan subjek untuk memahami pengalaman afektif, dalam rangka meningkatkan harga diri dan kepercayaan diri ketika menghadapi tantangan baru (Feldman, Joormann, \& Johnson, 2008). Akibatnya terjadi hipersensitivitas terha- dap stimulus afektif yang dianggap menyenangkan.

Setelah memperhitungkan peran alexithymia dan rumination pada level trait global maupun pada level dimensi, trait self-control memiliki kontribusi dalam memprediksi rating valence, yaitu subjek dengan kapasitas self-control yang lebih unggul melaporkan perasaan yang lebih tidak menyenangkan terhadap stimulus netral. Jika dikaitkan dengan teori feedback loops (Carver \& Scheier, 1982), selama fase Testing dari siklus TOTE (Test-OperateTest-Exit), keberadaan afek negatif dibutuhkan dalam kadar tertentu agar selfcontrol dapat teraktivasi. Dalam sebuah studi, subjek cenderung mengidentifikasi target yang sebetulnya netral (kata-kata berbahasa Jerman dan Cina) sebagai stimulus negatif setelah diinduksi dengan tugas self-control sederhana berupa incongruent Stroop task (Fritz \& Dreisbach, 2013). Afek negatif, rasa sakit, dan selfcontrol berada pada area anterior cingulate cortex yang membantu subjek menilai sejauh mana suatu stimulus berpotensi menghasilkan imbalan dan hukuman, serta merencanakan respons adaptif yang harus segera ia tampilkan (diskusi lebih lanjut, lihat Medford \& Critchley, 2010). Pada subjek yang memiliki trait self-control tinggi, afek negatif biasanya tidak berlangsung lama karena didukung kemampuan untuk segera menghadapi potensi konflik melalui mobilisasi kontrol (Inzlicht, Bartholow, \& Hirsh, 2015).

Prediksi atas rating arousal dalam penelitian ini ditemukan dari dimensi DIF pada trait alexythimia, yaitu subjek yang kesulitan mengidentifikasi perasaannya sendiri memberikan rating arousal yang tinggi diberikan terhadap kategori stimulus negatif-arousal tinggi. Temuan ini sejalan penelitian Karlsson, Näätänen, dan Stenman (2008) yang menyimpulkan 
bahwa partisipan dengan alexythimia melaporkan kemarahan setelah menyaksikan film humor, perasaan jijik setelah menyaksikan film sedih, dan rating arousal yang lebih tinggi pula terhadap elemen film yang mengancam. Mekanisme di balik hal ini masih spekulatif, namun partisipan dalam penelitian tersebut menunjukkan aktivasi area anterior insular cortex yang lebih terkait dengan sensasi ketubuhan yang muncul akibat stimulus afektif dan bukan terhadap konten afektif yang ditampilkan. Area anterior insular cortex lebih banyak merespons terhadap dimensi arousal (Colibazzi, Posner, Wang, Gorman, Gerber, Yu, \& Russell, 2010), sehingga menurunkan akurasi penilaian terhadap stimulus.

Sebagai tambahan, partisipan perempuan menunjukkan pola rating valence yang berbeda dengan laki-laki, bahkan setelah memperhitungkan peran trait alexythimia, rumination, dan self-control. Perempuan memberikan rating valence lebih rendah (tidak menyenangkan) terhadap stimulus netral dan negatif, dan menunjukkan preferensi terhadap stimulus positif dengan arousal rendah yang memicu perasaan kalem, relaks, dan damai. Temuan ini seakan bertentangan dengan mitos perempuan sebagai "makhluk emosional" vs. laki-laki "makhluk rasional". Meskipun demikian, perbedaan jenis kelamin terkait pula dengan pebedaan fokus aktivitas neural karena perempuan cenderung terfokus pada pengalaman internal dan laki-laki pada stimulus visual eksternal (Moriguchi, Touroutoglou, Dautoff, Dickerson, \& Barrett, 2014). Artinya rating valence rendah mungkin diakibatkan oleh jenis stimulus yang relatif tidak membangkitkan pengalaman internal kaum perempuan.

\section{Kesimpulan}

Trait alexithymia dan rumination, walaupun terkesan sebagai trait yang berlawanan dalam konteks pengalaman afektif, menunjukkan korelasi yang positif sehingga cenderung meningkat atau menurun secara simultan pada individu yang sama. Dampak buruk kedua trait ini yang secara teoretis dapat dihambat oleh trait selfcontrol diindikasikan dari asosiasi negatif antara self-control dan alexythimia khususnya terkait dengan kesulitan melakukan identifikasi dan memberikan deskripsi atas perasaan diri sendiri. Tidak signifikannya korelasi trait self-control dan rumination secara global maupun pada level dimensi memperlihatkan bahwa aktivasi keterkaitan kedua trait tersebut membutuhkan pertimbangan mengenai tema pengalaman afektif yang dihadapi individu.

Peran trait alexithymia dan rumination dalam struktur pengalaman afektif tidak muncul pada level trait global namun pada level dimensi dari masing-masing trait, dalam konteks kombinasi valence dan arousal stimulus tertentu. Hipersensitivitas terhadap stimulus afektif yang menyenangkan sejalan dengan kecenderungan berfokus terhadap dunia luar pada trait alexythimia dan kritik terhadap diri pada trait rumination. Sementara peningkatan perasaan marah, takut, jijik, dan grief (kombinasi valence negatif, arousal tinggi) terprediksi melalui kesulitan subjek mengidentifikasi perasaan diri sendiri pada trait alexythimia. Setelah memperhitungkan peran trait alexythimia dan rumination, self-control menjadi teraktivasi melalui keberadaan afek negatif yang diatribusikan terhadap stimulus netral.

Saran

Stimulus IAPS selain memiliki variasi nilai valence dan arousal juga mengandung 
beragam konten tematik mulai dari foto hewan, ekspresi wajah, mutilasi, erotis, pemandangan, kekerasan, objek, olahraga, dan polusi. Penelitian selanjutnya dapat menguji respons individu terhadap masing-masing parameter, dengan cara membandingkan stimulus yang setara dalam valence dan arousal namun memiliki kualitas konten yang berbeda (lihat Bernat, Patrick, Benning, \& Tellegen, 2006). Konsistensi temuan dalam penelitian ini perlu digali melalui jenis stimulus nonverbal lain (auditori atau olfaktori) maupun stimulus verbal (kata-kata atau narasi). Studi dengan data biologis terukur sangat dibutuhkan sebagai komparasi kesesuaian rating subjektif yang dihasilkan dari penelitian ini dengan proses emosiafek yang lebih mendasar. Selain itu, dinamika peran trait rumination, alexythimia, dan self-control perlu diteliti pada konteks pengalaman afektif lebih kompleks terkait emosi yang counterfactual seperti penyesalan dalam pengambilan keputusan (Hidayat, 2011) maupun pada konteks sosial seperti stigma (Yusainy, Thohari \& Gustomy, 2016).

\section{Kepustakaan}

Badan Penelitian \& Pengembangan Kesehatan (2013). Riset Kesehatan Dasar. Jakarta: Kementerian Kesehatan Republik Indonesia.

Bagby, R. M., Parker, J. D. A. \& Taylor, G. J. (1994). The twenty-item Toronto Alexithymia Scale-I. Item selection and cross-validation of the factor structure. Journal of Psychosomatic Research, 38, 23-32. doi:10.1016/00223999(94)90005-1

Baumeister, R. F., \& Alghamdi, N. G. (2015). Role of self-control failure in immoral and unethical actions. Current Opinion in Psychology, 6, 66-69. doi:10.1016/j.copsyc.2015.04.001
Baumeister, R. F., Gailliot, M., DeWall, C. N., \& Oaten, M. (2006). Self-regulation and personality: How interventions increase regulatory success, and how depletion moderates the effects of traits on behavior. Journal of Personality, 74(6), 1773-1801. doi: 10. 1111/j.1467-6494.2006.00428.x

Bernat, E., Patrick, C. J., Benning, S. D., \& Tellegen, A. (2006). Effects of picture content and intensity on affective physiological response. Psychophysiology, 43(1), 93-103. doi: 10.1111/ j.1 469-8986.2006.00380.x

Bradley, M. M. (2009). Natural selective attention: Orienting and emotion. Psychophysiology, 46, 1-11. doi: 10. 11 11/j.1469-8986.2008.00702.x

Bradley, M. M. \& Lang, P. J. (2007). The International Affective Picture System (IAPS) in the study of emotion and attention. In J. A. Coan and J. J. B. Allen (Eds.), Handbookof Emotion Elicitation and Assessment (pp. 29-46). Oxford University Press.

Carver, C. S., \& Scheier, M. F. (1982). Control theory: A useful conceptual framework for personality-social, clinical and health psychology. Psychological Bulletin, 92(1), 111-135. doi: 10.1037/0033-2909.92.1.111

Colibazzi, T., Posner, J., Wang, Z., Gorman, D., Gerber, A., Yu, S., \& Russell, J. A. (2010). Neural systems subserving valence and arousal during the experience of induced emotion. Emotion, 10, 377-389. doi: 10. 1177/0003065113484061

Damasio, A. R. (1999). The feeling of what happens: Body and emotion in the making of consciousness. New York: Harcourt Brace.

De Ridder, D. T., Lensvelt-Mulders, G., Finkenauer, C., Stok, F. M., \& 
Baumeister, R. F. (2012). A metaanalysis of how trait self-control relates to a wide range of behaviors. Personality and Social Psychology Review, 16(1), 76-99. doi: 10.1177/ 1088868311418749

Denson, T. F. (2013). The multiple systems model of angry rumination. Personality and Social Psychology Review, 17(2), 103-123. doi: $10.1177 / 108886831246$ 7086

Department of Health. (2011). No Health without Mental Health: A crossGovernment mental health outcomes strategy for people of all ages - a call to action. London: Department of Health.

Feldman Barrett, L., \& Russell, J. A.(1999). The structure of current affect: Controversies and emerging consensus. Current Directions in Psychological Science, 14, 10-14. doi: 10.1111/14678721.00003

Feldman, G. C., Joormann, J., Johnson, S. L. (2008). Responses to positive affect: A self-report measure of rumination and dampening. Cognitive Therapy and Research, 32, 507-525. doi: 10.1007/ s10608-006-9083-0

Freund, S. (2012). An examination of the cognitive, affective, and physiological aspects of alexithymia. Electronic Theses and Dissertations, Paper 4805. Canada: University of Windsor.

Friese, M., \& Hofmann, W. (2009). Control me or I will control you: Impulses, trait self-control, and the guidance of behavior. Journal of Research in Personality, 43(5), 795-805. doi: 10.1016/ j.jrp.2009.07.004

Fritz J., \& Dreisbach, G. (2013). Conflicts as aversive signals: Conflict priming increases negative judgments for neutral stimuli. Cognitive Affective
Behavioral Neuroscience, 13, 311-317. doi: 10.3758/s13415-012-0147-1

Gross, J. J. (Ed.). (2007). Handbook of emotion regulation. New York: Guilford.

Heinzel, A., Schafer, R., Muller, H., Schieffer, A., Ingenhag, A., Northoff, G., Franz, M., \& Hubertus, H. (2010). Differential modulation of valence and arousal in high-alexithymic and low-alexithymic individuals. Neuro Report, 21, 998-1002. doi: 10.1097/ WNR.0b013e32833f38e 0

Henry, J. D., Phillips, L. H., Crawford, J. R., Theodorou, G., \& Summers, F. (2006). Cognitive and psychosocial correlates of alexithymia following traumatic brain injury. Neuropsychologia, 44, 62-72. doi: 10.1016/ j.neuropsychologia.2005.04.011

Hidayat, R. (2011). Regret and topical accounting: Is cyclical bidding the bases of the laboratory winner's curse? Jurnal Psikologi, 38(2), 185-198. doi: 10.22146/jpsi.7652

Inzlicht, M., Bartholow, B. D., \& Hirsh, J. B. (2015). Emotional foundations of cognitive control. Trends in Cognitive Sciences, 19(3), 126-132. doi: 10.1016/ j.tics.2015.01.004

Inzlicht, M., \& Legault, L. (2014). No pain, no gain: How distress underlies effective self-control (and unites diverse social psychological phenomena). In J. Forgas \& E. Harmon-Jones (Eds.), The control within: Motivation and its regulation (pp. 115-132). New York: Psychology Press.

Izard, C. E. (2010). The many meanings/ aspects of emotion: Definitions, functions, activation, and regulation. Emotion Review, 2, 363-370. doi: 10. 1177/1754073910374661

Karlsson, H., Naatanen, P., Stenman. H. (2008). Cortical activation in 
alexithymia as a response to emotional stimuli. British Journal of Psychiatry, 192, 32-38. doi: 10.1192/ bjp.bp. 106. 034728

Lang, P. J. (1980). Behavioral treatment and bio-behavioral assessment: Computer applications. In J. B. Sidowski, J. H. Johnson, \& T. A. Williams (Eds.), Technology in mental health care delivery systems (pp. 119-137). Norwood, NJ: Ablex.

Lang, P. J., Bradley, M. M., \& Cuthbert, B. N. (2008). International affective picture system (IAPS): Affective ratings of pictures and instruction manual. Technical Report A-8. University of Florida, Gainesville, FL.

Loas, G., Corcos, M., Stephan, P., Pellet, J., Bizouard, P., Venisse, J. L., Perez-Diaz, F., Guelfi, J. D., Flament, M., \& Jeammet, P. (2001). Factorial structure of the 20-item Toronto Alexithymia Scale confirmatory factorial analyses in nonclinical and clinical samples. Journal of Psychosomatic Research, 50(5), 255-261. doi: 10.1016/ j.psychres. 2014. 12.013

Medford, N., \& Critchley, H. D. (2010). Conjoint activity of anterior insular and anterior cingulate cortex: Awareness and response. Brain Structure and Function, 214(5-6), 535-549. doi: 10. 1007/s00429-010-0265-x

Moffitt, T., Arseneault, L., Belsky, D., Dickson, N., Hancox, R., Harrington, H. L., .. Caspi, A. (2011). A gradient of childhood self-control predicts health, wealth, and public safety. Proceedings of the National Academy of Sciences, 108(7), 2693-2698. doi: 10. 1073/ pnas.1010076108

Moriguchi, Y., Touroutoglou, A., Dautoff, R., Dickerson, B.C., Barrett, L. F. (2014). Sex differences in the neural correlates of affective experience.
Social Cognitive and Affective Neuroscience, 9(5), 591-600. doi:10.1093/ scan/nst030

Nolen-Hoeksema, S. (1991). Responses to depression and their effects on the duration of depressive episodes. Journal of Abnormal Psychology, 100, 569-582. doi: 10.1037//0021-43X. 100. 4. 569

Nolen-Hoeksema, S., Larson, J., \& Grayson, C. (1999). Explaining the gender difference in depressive symptoms. Journal of Personality and Social Psychology, 77(5), 1061-1072. doi: 10.1037/0022-3514.77.5.1061

Nolen-Hoeksema, S., Wisco, B. E., \& Lyubomirsky, S. (2008). Rethinking rumination. Perspectives on Psychological Science, 3(5), 400-424. doi: 10. 1111/j.1745-6924.2008.00088.x

Panksepp, J., \& Biven, L. (2012). The archaeology of mind: Neuroevolutionary origins of human emotions. New York: W. W. Norton and Co.

Panayiotou, G. (2008). Emotional dimensions reflected in ratings of affective scripts. Personality and Individual Differences, 44, 1795-1806. doi: 10.1016/ j.paid.2008.02.006

Ray, R. D., Ochsner, K. N., Cooper, J. C.. Robertson, E. R., Gabrieli, J. D. E., \& Gross, J. J. (2005). Individual differences in trait rumination and the neural systems supporting cognitive reappraisal.Cognitive, Affective, and Behavioral Neuroscience, 5(2), 156-168. doi: 10.3758/CABN.5.2.156

Russell, J. A. (2003). Core affect and the psychological construction of emotion. Psychological Review, 110, 145-172. doi: 10.1037/0033-295X.110.1.145

Swart, M., Kortekaas, R., \& Aleman, A. (2009). Dealing with feelings: Characterization of trait alexithymia 
on emotion regulation strategies and cognitive-emotional processing. PLoS ONE, 4(6), e5751. doi: 10.1371/ journal.pone.0005751/

Tangney, J. P., Baumeister, R. F., \& Boone, A. L. (2004). High self-control predicts good adjustment, less pathology, better grades, and interpersonal success. Journal of Personality, 72(2), 271-322. doi: 10.1111/j.0022-3506. 2004. 00263.x

Taylor, G. J., Bagby, R. M., \& Parker, J. D. A. (2003). The 20-Item Toronto Alexithymia Scale IV. Reliability and factorial validity in different languages and cultures. Journal of Psychosomatic Research, 55(3), 277-283. doi: 10.1016/S0022-3999(02)00601-3

Treynor, W., Gonzalez, R., \& NolenHoeksema, S. (2003). Rumination reconsidered: A psychometric analysis. Cognitive Therapy and Research, 27, 247-259. doi: 10.1023/A:1023910315561
Whitmer, A, \& Gotlib, I. H. (2011). Brooding and reflection reconsidered: A factor analytic examination of rumination in currently depressed, formerly depressed, and never depressed individuals. Journal Cognitive Therapy and Research, 35(2), 99-107. doi: 10.1007/s10608-011-9361-3

Williams, J. M. (2010). Mindfulness and psychological process. Emotion, 10(1), 1-17. doi: 10.1037/a0018360

Yusainy, C., \& Lawrence, C. (2015). Brief mindfulness induction could reduce aggression after depletion. Consciousness and Cognition, 33(1), 125-134. doi: 10.1016/j.concog.2014.12.008

Yusainy, C., Thohari, S., \& Gustomy, R. (2016). \#StopAbleism: Reduksi stigma kepada penyandang disabilitas melalui intervensi bias implisit. Jurnal Psikologi, 43, 1-15. doi: 10.22146/ jpsi.9168.

(i) Penelitian ini terselenggara atas dana BOPTN Fakultas Ilmu Sosial dan Ilmu Politik Universitas Brawijaya.

(ii) Peneliti mengucapkan terima kasih kepada Ignatius Ryan Jeffri Dharmawan, Bima Pustaka Semedhi, dan Riska Andari atas bantuan dalam pengumpulan data. 